\title{
Total Asymmetric Synthesis of Monosaccharides and Analogues
}

\author{
Inmaculada Robina*, Ana T. Carmona, Antonio J. Moreno-Vargas, and Elena Moreno-Clavijo
}

\begin{abstract}
Since the discovery of the 'formose reaction' by Butlerow, ${ }^{[1]}$ total synthesis of carbohydrates has undergone rapid development. The most important methods for the asymmetric synthesis of monosaccharides and analogues of biological importance are presented. Nowadays any natural and non-natural monosaccharide can be prepared pure in both enantiomeric forms starting from inexpensive starting materials. Metal-based asymmetric catalysis and organocatalysis have been successfully applied, alone or in combination with chemoenzymatic methods. Alternative methods rely upon substrate- or reagent- controlled diastereo- and enantioselective reactions. Suitably protected carbohydrates have been prepared by total synthesis, thus allowing their direct use in the preparation of oligosaccharides and analogues. ${ }^{[2]}$
\end{abstract}

Keywords: Aldolase · Allylation · Asymmetric aldol · Chain elongation · Dihydroxylation · Epoxidation · Hetero-Diels-Alder · Organocatalysis

\section{Applications of Chemo- enzymatic Methods and Organocatalysis}

\subsection{Aldolase-catalyzed Asymmetric Aldol Condensations}

The enzymatic aldol addition in the presence of type I and II aldolases ${ }^{[3]}$ represents a useful method for the synthesis of various sugars and sugar-like structures. ${ }^{[4]}$ Thus, D- and L-fructose are prepared from dihydroxyacetone monophosphate (DHAP) and D- and L-glyceraldehyde (Scheme 1), in the presence of rabbit muscle aldolase (RAMA) or L-rhamnulose 1-phosphate (Rha) aldolase. ${ }^{[5]}$

The method also works to generate (-)-1-deoxymannonojirimycin (1) and (+)-1-deoxynojirimycin (2) ${ }^{[3]}$ using fructose-1,6-diphosphate (FDP) aldolase ${ }^{[6]}$ catalyzing the key $\mathrm{C}-\mathrm{C}$ bond forming step and further transformations. Similarly, fuculose-1-phosphate (Fuc-1-P) aldolase catalyzes the aldolization between DHAP and ( \pm )-3-azido-2-hydroxypropanal leading to ketose $\mathbf{3}$ which after reduction provided (+)-1-deoxygalactostatine (+)-4[3] (Scheme 2)

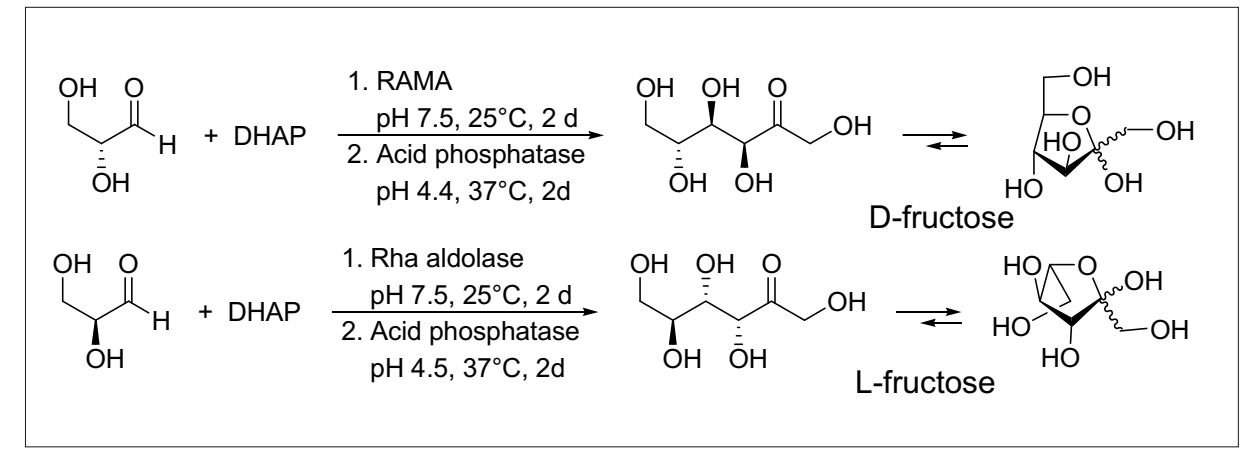

Scheme 1. Syntheses of L- and D-fructose.

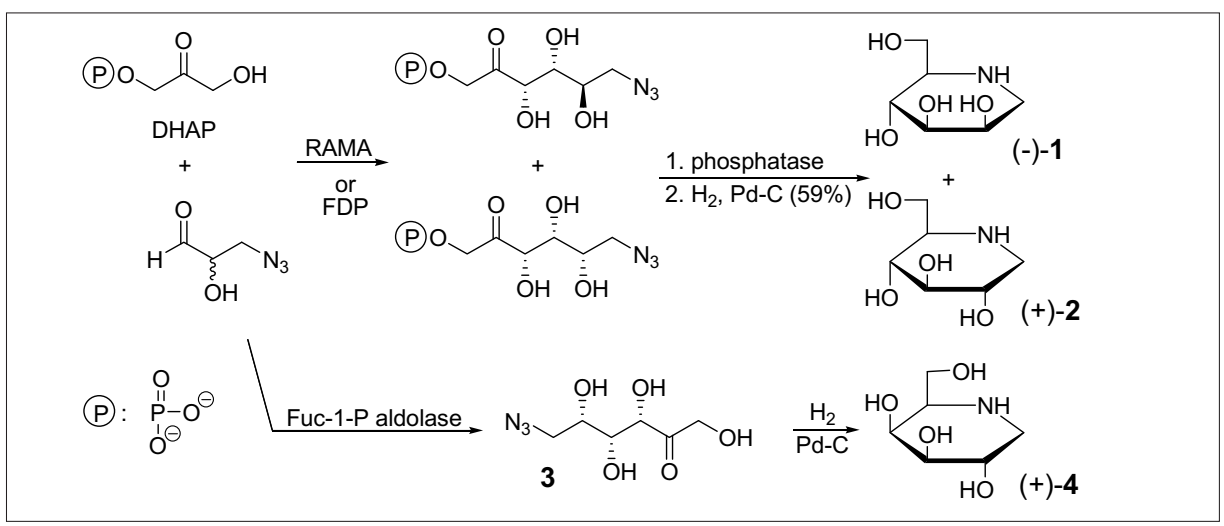

Scheme 2. Chemoenzymatic synthesis of 1,5-dideoxy-1,5-imino-alditols.

Similarly, pyrrolidines are obtained from 2-azidoaldehydes as substrates in the RAMA-catalyzed aldol reaction with DHAP followed by reduction. ${ }^{[3,7]}$ 2-Deoxy-5-thio-D-erythro-pentose was obtained by catalyzed 2-deoxyribose- 5 phosphate aldolase (DERA) condensation between acetaldehyde and racemic 3-thioglyceraldehyde. ${ }^{[8]}$
1.2 Asymmetric Synthesis of Carbohydrates Applying Organocatalysis

The List ${ }^{[9]}$ proline-catalyzed intermolecular aldol reaction based on the intramolecular Hajos-Parrish-Eder-SauerWiechert reaction ${ }^{[10]}$ has been widely used in de novo synthesis of carbohydrates. In this reaction, enolizable achiral aldehydes and ketones are transformed into the corresponding enamines, which react with 
less enolizable carbonyl compounds, even in one-pot protocols. A metal-free partial Zimmerman-Traxler-type transition state has been postulated (Fig. 1). ${ }^{[1]}$

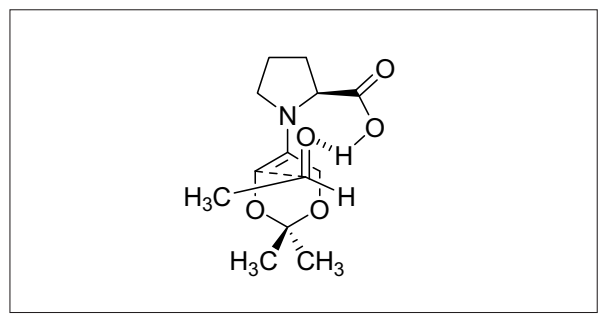

Fig. 1. Postulated transition state model.

Proline and derivatives, ${ }^{[12]}$ simple amino acids and peptides, ${ }^{[13]}$ and cyclic compounds $^{[14]}$ are effective asymmetric catalysts. Solid-supported proline-terminated peptides have also been used as heterogeneous catalysts for the asymmetric aldol reaction. ${ }^{[15]}$ An improvement of the stereochemical outcome of the reaction by using protected dihydroxyacetone variants such as 1,3-dioxan-5-one and 2,2-dimethyl-1,3-dioxan-5-one with aldehydes in the presence of $(S)$-proline $((S)$ Pro) and $(S)$-2-pyrrolidine-tetrazole was reported by Barbas III and co-workers. Reaction of 2,2-dimethyl-1,3-dioxan-5one (5) with appropriate aldehydes provided access to L-ribulose and D-tagatose (Scheme 3). ${ }^{[16]}$

Enders and co-workers ${ }^{[17]}$ reported the synthesis of various protected carbohydrates and aminosugars through highly diastereo- and enantioselective direct organocatalytic aldol reactions of $\mathbf{5}$ with appropriate aldehydes in the presence of $(S)$-proline. There is a matching correspondence between $\alpha$-branched $(S)$ or $(R)$-configurated aldehydes and $(S)$ or $(R)$ proline, respectively. A similar route was reported by Córdova and co-workers.[18] McMillan and co-workers ${ }^{[19]}$ reported the first example of direct enantioselective aldehyde-aldehyde cross-aldol reaction using small molecules as catalysts, e.g. the Lproline-catalyzed aldol reaction generates hexoses. ${ }^{[20]}$ By combining L-erythrose derivative 6 obtained by L-proline-catalyzed dimerization of (t-Bu) $\mathrm{Ph}_{2} \mathrm{Si} \mathrm{OCH} \mathrm{OCHO}_{2} \mathrm{CH}$ with enoxysilane 7 in Mukaiyama aldol reactions catalyzed by various Lewis acids, McMillian and co-workers have realized efficient, two-step synthesis of semiprotected L-glucose (8) and L-mannose (9) (Scheme 4). The method was also applied to L-allose derivatives. ${ }^{[21]}$

Highly enantioselective double aldol reaction of benzyloxyacetaldehyde using various $\alpha$-amino acids as organocatalysts in water was reported by Córdova and co-workers. ${ }^{[22]}$ They also reported tandem

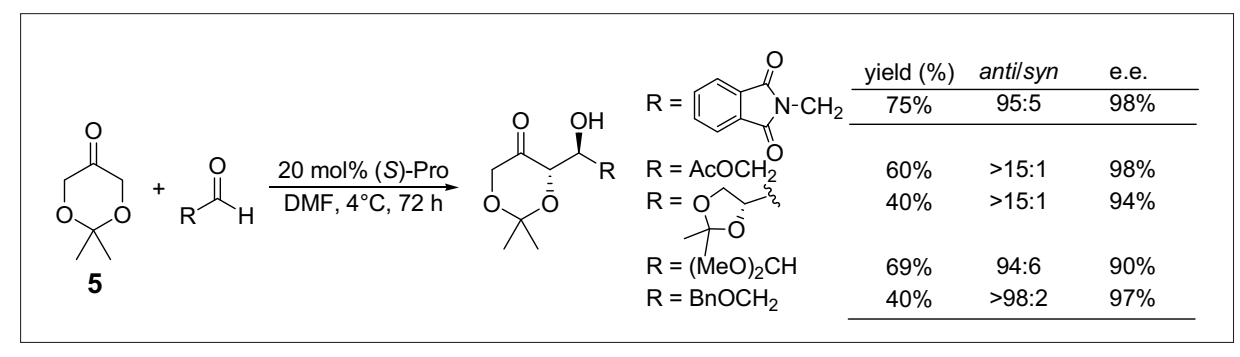

Scheme 3. Stereoselective L-proline-catalyzed aldol reaction.

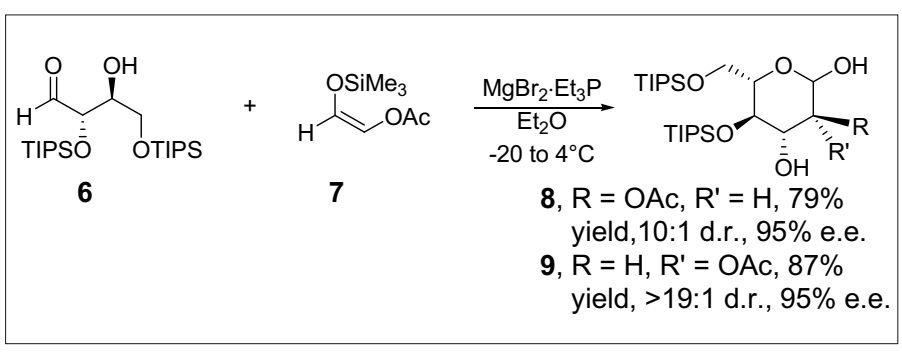

Scheme 4. Two-step syntheses of L-glucose and L-mannose derivatives.

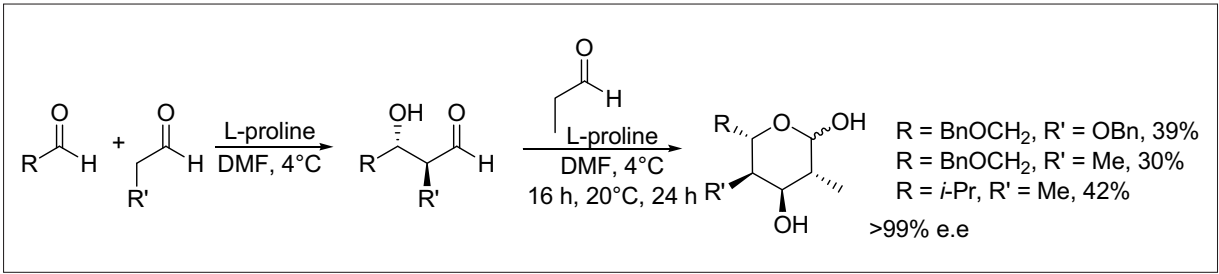

Scheme 5. Córdova's two-step syntheses of deoxyaldoses and polyketides.

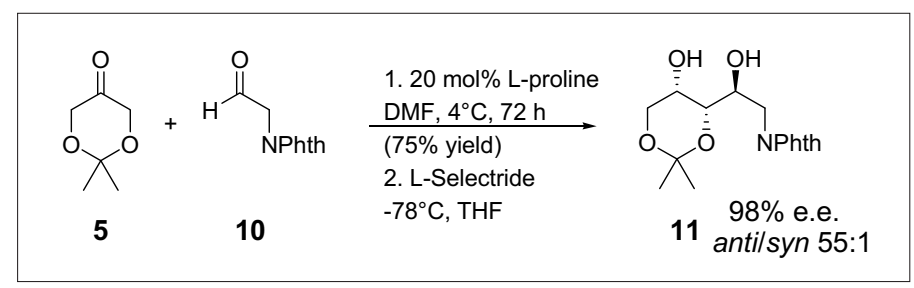

Scheme 6. Barbas' synthesis of aminoalditols.

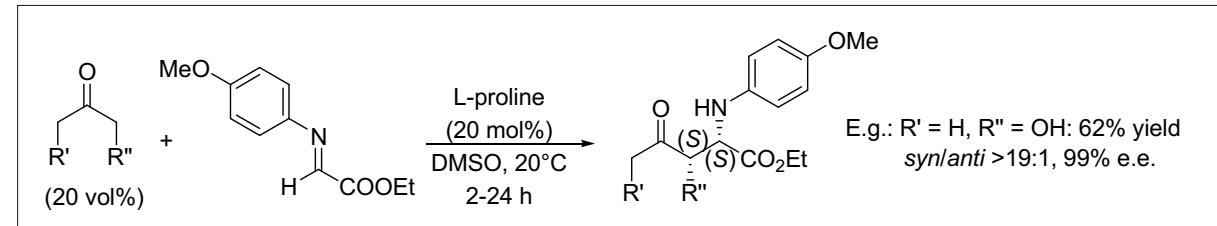

Scheme 7. Barbas' L-proline catalyzed asymmetric Mannich reactions.

two-step iterative aldol reaction with aldehydes for the synthesis of natural/unnatural hexoses (Scheme 5). [23]

Barbas and co-workers reported the preparation of $\alpha$-aminosugars and derivatives by direct organocatalytic asymmetric aldol reaction of $\alpha$-aminoaldehydes. For instance, the reaction of $\mathbf{5}$ with phthalimido aldehyde $\mathbf{1 0}$ followed by stereoselective reduction of the carbonyl moiety afforded protected aminoalditol 11 (Scheme 6). ${ }^{[16]}$

In a similar way, Enders and co-workers have prepared D-erythro-pentos-4-ulose, 5-amino-5-deoxy-L-psicose and 5-amino5-deoxy-L-tagatose derivatives. ${ }^{[17]}$ The pro- line-catalyzed Mannich reaction was applied by Barbas and co-workers as depicted in Scheme 7.[24]

A similar reaction was applied by List and co-workers for the synthesis of $\beta$-aminocarbonyl compounds. ${ }^{[25]}$

These reactions exhibit opposite enantiofacial selectivity to the proline-catalyzed aldol reaction. The attack to the $s i$-face is preferred (Scheme 8)

A three-component Mannich reaction with several aldehydes and $p$-anisidine with L-proline as organocatalyst was used by Enders for the synthesis of aminopentoses and aminohexoses. ${ }^{[26]}$ This reaction 


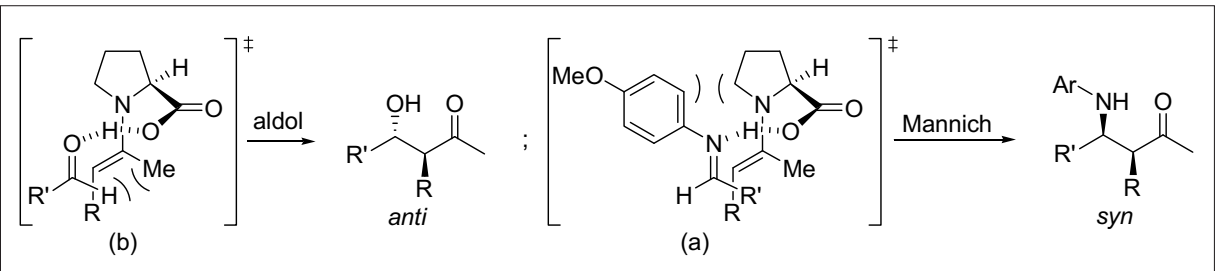

Scheme 8. Proposed transition states for the L-proline-catalyzed asymmetric Mannich and aldol reactions.

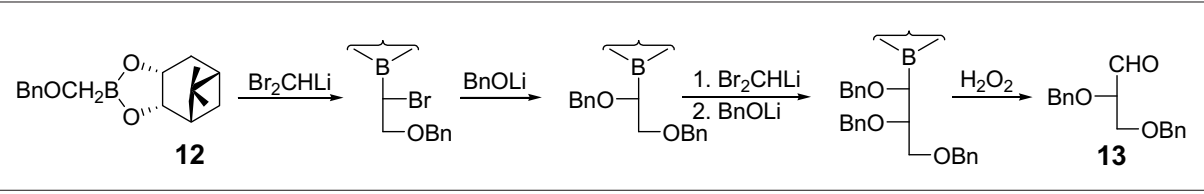

Scheme 9. Asymmetric chain elongation of dibromomethyllithium.

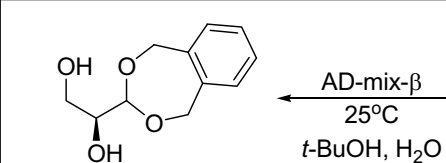

$(S)-15$

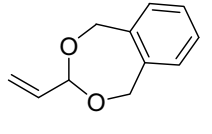

14

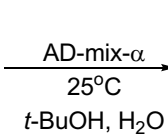

$t-\mathrm{BuOH}, \mathrm{H}_{2} \mathrm{O}$

Scheme 10. Sharpless asymmetric dihydroxylation applied to the syntheses of C(3)-sugar precursors.

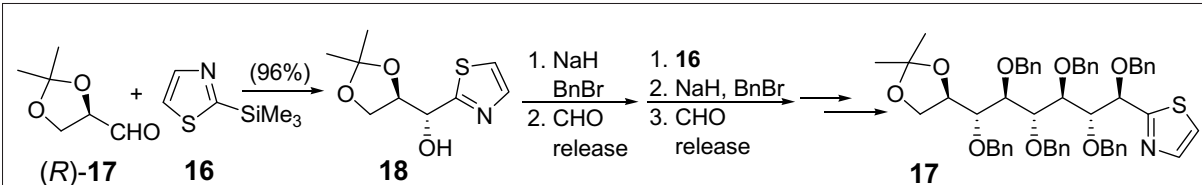

Scheme 11. Dondoni's one-carbon chain elongation.

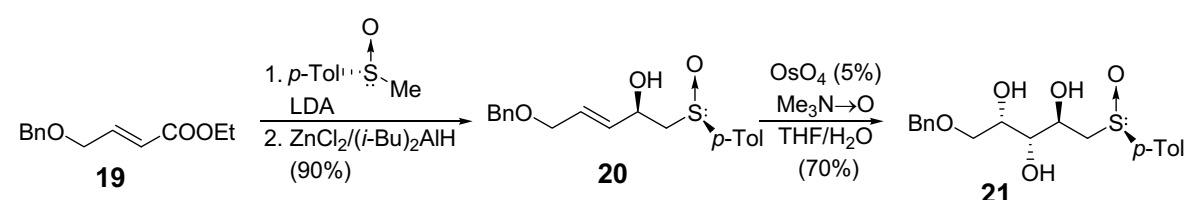

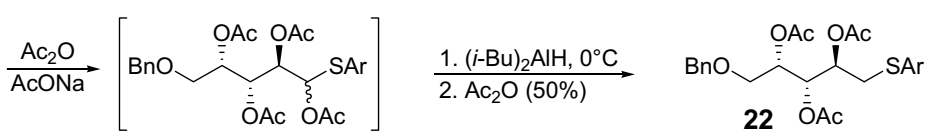

Scheme 12. Asymmetric synthesis of L-arabinitol derivatives via stereoselective dihydroxylation of an enantiomerically pure allylic alcohol.

was also studied by Hayashi and co-workers. ${ }^{[27]}$

\section{Chain Elongation of Aldehydes}

\subsection{Nucleophilic Additions to Aldehydes}

Chemical asymmetric cross-aldol condensations using enantiomerically pure Lewis acids as promoters were used to prepare monosaccharides and analogues.[28] The classical Kiliani-Fischer cyanohydrin synthesis has been widely used in spite of its low diastereoselectivity and harsh reaction conditions. ${ }^{[29]}$ More flexible and highly selective methods are currently used such as aldehyde allylation with allyl boronates ${ }^{[30]}$ or with allylstannanes. ${ }^{[31]} \mathrm{D}$ - and L-glyceraldehyde and derivatives are widely used chirons. Chain extension using an insertion reaction of dichloromethyllithium or dibromomethyl-lithium with (S)-pinanediol [(benzyloxy)methyl]boronate $\mathbf{1 2}$ was used to generate $\mathrm{L}-\mathrm{C}_{3}, \mathrm{~L}-\mathrm{C}_{4}$ and $\mathrm{L}-\mathrm{C}_{5}$-aldoses. Two successive insertion reactions gave protected L-glyceraldehyde 13 ${ }^{32]}$ (Scheme 9).

Sharpless asymmetric dihydroxylation of the benzene-1,2-dimethanol acetal of acrolein (14) furnished protected forms of L- and D-glyceraldehyde (Scheme 10). ${ }^{[33]}$
Dondoni and co-workers have developed highly anti-selective homologation of $\alpha$-hydroxycarbaldehydes and $\alpha$-hydroxylactones by addition of 2-(trimethylsilyl)thiazole (16) to chiral aldehydes. From D- and L-glyceraldehydes, D- and L-erythro configured derivatives are obtained. ${ }^{[34]}$ Chain elongation to the corresponding all-anti configurated nonose $\mathbf{1 7}$ derivative was performed by iterative additions and unmasking protocols (Scheme 11). Dondoni's methodology was applied to the preparation of other aldose configurations ${ }^{[35]}$ and all kinds of aminosugars. ${ }^{[36]}$

Other alternative one-carbon chain elongation of aldoses are the nitroaldol condensation $^{[37]}$ and the methodologies reported by Kusanabe and Sato, ${ }^{[38]}$ and Chikashita and co-workers. ${ }^{[39]}$

The addition of $(+)-(R)$-methyl $p$-tolylsulfoxide to $\alpha, \beta$-unsaturated esters in the presence of LDA gave the corresponding ketosulfoxides which were reduced into $\beta$-hydroxy sulfoxides that were converted into L-arabinitol derivatives. Thus, starting from 19, allylic alcohol 20 was obtained which after dihydroxylation, Pummerer rearrangement and subsequent reduction and acetylation gave thioarabinitol $\mathbf{2 2}$ (Scheme 12). ${ }^{[40]}$

\subsection{Asymmetric Aldol Reactions}

Cross-aldolization of crotonaldehydes (23) and enoxysilane 24 under Mukaiyama conditions gave the corresponding anti-aldols that were further transformed into several sugars as indicated in Scheme 13.[28,41]

Kobayashi and Kawasuji[28b] prepared L-fucose from $(E)$-crotonaldehyde applying an analogous method.

Conversion of $\left((R)\right.$ - 'HYTRA' $^{[422]}$ into its lithium enolate and subsequent addition to acrolein gave (1'R,3R)-26 (diastereoselectivity: 92:8) which was transformed into a iodolactone precursor of several 2-deoxyfuranosides 27a-c (Scheme 14). ${ }^{[43]}$

Diastereoselective aldol reaction of an Evans' homochiral enolate with crotonaldehyde gave the syn aldol that was transformed into the Weinreb amide, a potential precursor of all kinds of monosaccharides and analogues, including 1-deoxynojirimycin. ${ }^{[44]}$ Enders and Jegelka prepared enantiomerically pure $\mathrm{C}_{5}$ - to $\mathrm{C}_{9}$-deoxycarbohydrates using RAMP/SAMP derivatives and 5. ${ }^{[45]}$

\subsection{Aldehyde Olefination and Asymmetric Epoxidation}

Wittig olefination of D-glyceraldehyde acetonide with $\mathrm{Ph}_{3} \mathrm{P}=\mathrm{CHCHO}$ and reduction of the enal gave the corresponding (E)-allylic alcohol, which upon Katsuki-Sharpless enantioselective epoxidation $^{[46]}$ furnished D-arabinitol (= D-lyxitol) and ribitol. Similarly, olefination with $\mathrm{Ph}_{3} \mathrm{P}=\mathrm{CHCH}(\mathrm{OEt})_{2}$, acidic hydrolysis of 


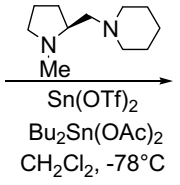

25a $\left(\mathrm{R}=\mathrm{H}, \mathrm{R}^{\prime}=\mathrm{H}\right)$
$25 \mathrm{~b}\left(\mathrm{R}=\mathrm{H}, \mathrm{R}^{\prime}=\mathrm{Me}\right)$

25b $\left(R=H, R^{\prime}=M e\right)$
25 $\left(R=M e, R^{\prime}=H\right)$<smiles>[R]C=C([R])C([CH])=O</smiles>

$23 a\left(R=H, R^{\prime}=H\right) 24$ 23b $\left(R=H, R^{\prime}=M e\right)$ 23c $\left(R=M e, R^{\prime}=H\right)$
D-ribose; 4-C-methyl-D-ribose; 6-deoxy-L-talose

13. Mukaiyama's asyn ribose and 6-deoxy-L-talose.

Scheme 14. Diastereoselective aldol reaction with $(R)$-'HYTRA'.

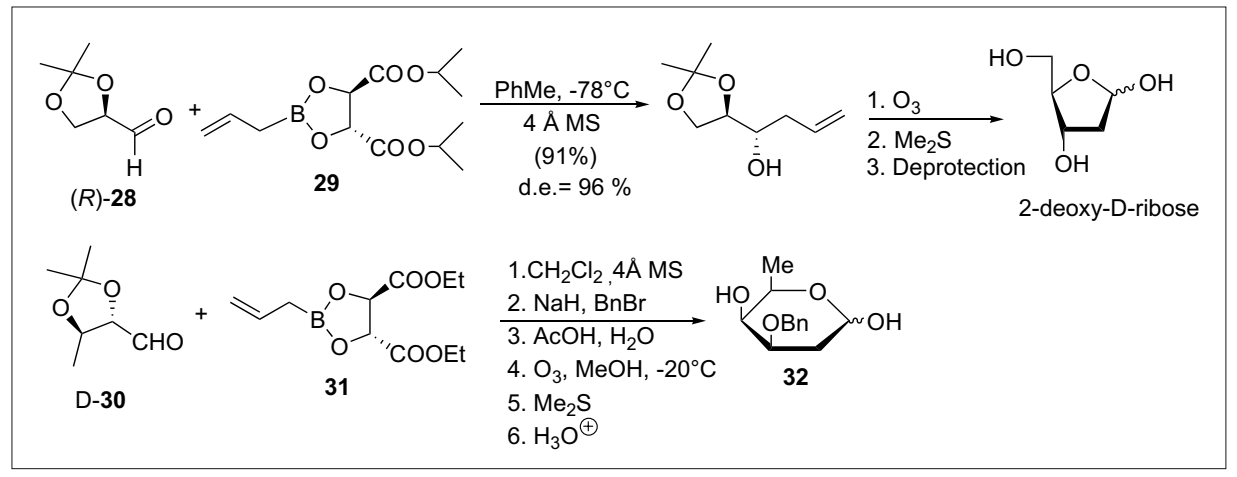

Scheme 15. Roush's synthesis of 2-deoxyaldoses.

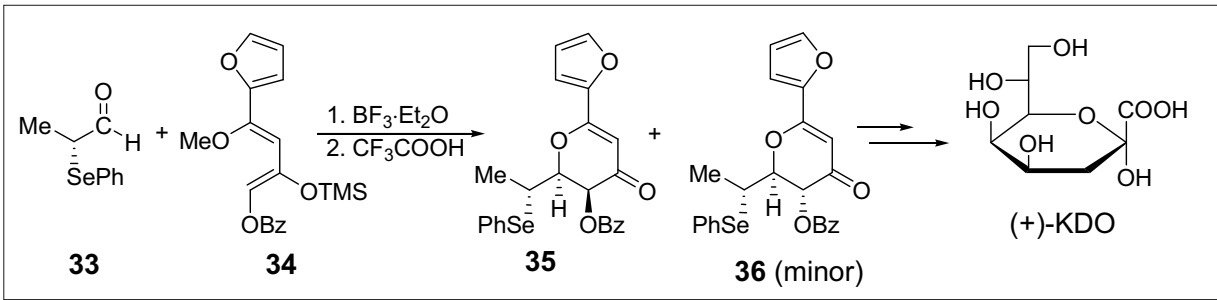

Scheme 16. Danishefsky's total synthesis of (+)-KDO.

the diethyl acetal and subsequent reduction of the enal provided the $(Z)$-allylic alcohol. Subsequent diastereoselective epoxidation and hydrolysis lead to D-arabinitol or $\mathrm{xy}$ litol.[47] The synthesis of all tetroses and hexoses developed by Sharpless and Masamune uses also the Katsuki-Sharpless asymmetric epoxidation of $(E)$-allylic alcohols as key-step. The epoxides obtained by oxidation of $(E)-4-(O$-protected)but-2en-1-ol underwent a Payne rearrangement in the presence of $\mathrm{NaOH}$, giving terminal epoxides that were opened regioselectively by $\mathrm{PhSNa}$ to give phenylsulfides. Protection of the diols as acetonides, oxidation

\subsection{Aldehyde Olefination and Dihydroxylation}

Convenient olefination of D-glyceraldehyde to (E)-3-(2,2-dimethyl-1,3-dioxolan-4-yl)prop-2-en-1-ol followed by protection as silyl ether and subsequent Sharpless asymmetric dihydroxylation gave other alditol stereomers that can be converted into all kinds of $\mathrm{C}_{5}$-monosaccharide derivatives. ${ }^{[49]}$

\subsection{Allylation and Subsequent Ozonolysis}

2-Deoxypentoses can be prepared by two-carbon chain elongation of 2,3-Oisopropylidene-D-glyceraldehyde following Roush's allylation method based on the highly diastereoselective additions of homochiral allylboronates derived from $(R, R)$ - and $(S, S)$-tartaric acid.[50] For instance, the synthesis of 2-deoxy-D-ribose and 2-deoxy derivative $\mathbf{3 2}$ outlined in Scheme 15. Similarly, Roush and Straub ${ }^{[51]}$ obtained 2,6-dideoxyhexose derivatives.

\subsection{Hetero-Diels-Alder Additions}

The first total synthesis of (+)-KDO is based on the hetero-Diels-Alder addition of $\alpha$-selenoaldehyde $\mathbf{3 3}$ to the $\alpha$-furylsubstituted diene 34. ${ }^{[52]}$ The reaction gives an adduct mixture which on treatment with $\mathrm{CF}_{3} \mathrm{COOH}$ delivers a 5:1 mixture of cis/trans dihydropyrones $\mathbf{3 5}$ and $\mathbf{3 6}$. Pure $\mathbf{3 5}$ was further transformed into (+)-KDO through addition of methanol, benzoylation, oxidative elimination of the phenylseleno group and dihydroxylation followed by benzoylation of the corresponding diol. Final oxidation with $\mathrm{RuO}_{4}$ followed by esterification with diazomethane and deprotection gave the target KDO (Scheme 16).

Independently, Evans ${ }^{[53]}$ and Jørgensen $^{[54]}$ have shown that $\beta, \gamma$-unsaturated $\alpha$-keto ester 37 reacts with ethyl vinyl ether 38 in the presence of enantiomerically pure bisoxazoline copper(II) complex 39 as catalyst. Enantiomerically enriched dihydropyran 40 was thus obtained which was further converted into ethyl $\beta$-D-manno-pyranoside tetraacetate 41 (Scheme 17). ${ }^{[55]}$

\section{Conclusion}

Biocatalysis and organocatalysis are opening a large number of possibilities to the total asymmetric synthesis of carbohydrates and analogues. Because of the ease of application and the limited number of synthetic steps required to construct monosaccharides that are dressed up with adequate semi-protection, one can foresee that these catalytic procedures might surpass soon more traditional methodologies based on the delicate chemical derivation of natural carbohydrates. Additionally, an 


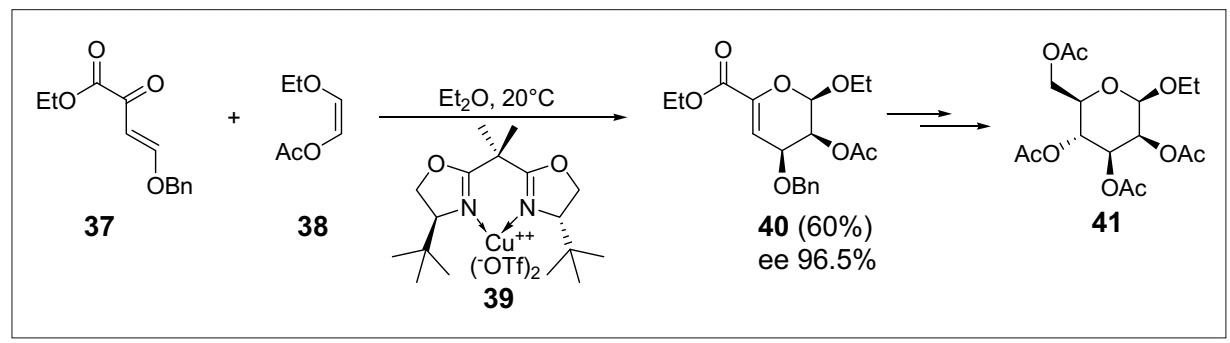

Scheme 17. Jørgensen's asymmetric synthesis of an ethyl $\beta$-D-mannopyranoside derivative.

arsenal of methods is now available for the stereoselective chain elongation of aldehydes and ketones based on substrate or/ and reagent control, or on asymmetric aldol reaction enantio-controlled by the chemical catalyst. Alternatively, olefination of aldehydes and subsequent Katsuki-Sharpless asymmetric epoxidation or Sharpless asymmetric dihydroxylation can be used (asymmetry controlled by the catalyst). The procedures can be applied to the construction of complicated monosaccharides and analogues of biological interest. These chemical methods are very well suited to generate long-chain carbohydrates, deoxyaldoses and alditols, aminodeoxy and aminodideoxy aldoses.

\section{Acknowledgements}

We thank the Ministerio de Ciencia e Innovación of Spain (CTQ2008-01565/BQU) and the Junta de Andalucía (FQM 345) for financial support.

Received: September 9, 2010

[1] a) M. A. Butlerow, CR Séances Acad. Sci. $\mathbf{1 8 6 1}$ 53, 145; b) M. A. Butlerow, Ann. Chem. 1861, 120, 295.

[2] For related references see: a) P. Vogel, in 'Encyclopedia of Glycosciences', Eds. B. FraserReid, K. Tatsuta, J. Thiem, Springer, Berlin, Germany, 2001, Vol. 2, Chapter 4.4, pp 1023; b) P. Vogel, in 'The Organic Chemistry of Sugars', Eds. D. E. Levy, P. Fugedi, CRC Taylor \& Francis Group, Boca Raton, FL, 2006, Chapter 13, pp 629; c) I. Robina, P. Vogel, in 'Comprehensive Glycoscience', Ed. J. Kamerling, Elsevier, Amsterdam, 2006, Vol. 1, pp. 489; d) I. Robina, P. Vogel, in 'Glycoscience, Chemistry and Chemical Biology', $2^{\mathrm{a}}$ ed., Ed. B. Fraser-Reid, K. Tatsuta, J. Thiem, Springer Verlag 2008, 857; e) I. Robina, P. Vogel, Chim. Oggi-Chem. Today 2007, 25, 65; f) I. Robina, P. Vogel, Chim. Oggi-Chem. Today, 2007, 25, 100; g) I. Robina, P. Vogel, Chim. OggiChem. Today 2007, 25, 104.

[3] See e.g. C.-C. Hsu, Z. Hong, M. Wada, D Franke, C.-H. Wong, PNAS 2005, 102, 9122

[4] a) C. H. Wong, R. L. Halcomb, Y. Ichikawa T. Kajimoto, Angew. Chem. Int. Ed. Engl. 1995, 34, 412; b) H. J. M. Gijsen, L. Qiao, W. Fitz, C.-H. Wong, Chem. Rev. 1996, 96 443; c) S. Takayama, G. J. McGarvey, C.-H Wong, Chem. Soc. Rev. 1997, 26, 407; d) T. D. Machajewski, C.-H. Wong, Angew. Chem Int. Ed. 2000, 39, 1352; e) M. G. Silvestri, G Desantis, M. Mitchell, C.-H. Wong, Topics in Stereochemistry 2003, 23, 267.

[5] D. Franke, T. Machajewski, C.-C. Hsu, C.-H. Wong, J. Org. Chem. 2003, 68, 6828 .
[6] C. H. Von der Osten, A. J. Sinskey, C. F. Barbas III, R. L. Pederson, Y.-F. Wang, C.-H. Wong, J. Am. Chem. Soc. 1989, 111, 3924.

[7] a) R. R. Hung, J. A. Straub, G. M. Whitesides, J. Org. Chem. 1991, 56, 3849; b) K. K.-C. Liu, T. Kajimoto, L. Chen, Z. Zhong, Y. Ichikawa, C.-H. Wong, J. Org. Chem. 1991, 56, 6280; c) T. Kajimoto, L. Chen, K. K. C. Liu, C.-H. Wong, J. Am. Chem. Soc. 1991, 113, 6678.

[8] C.-H. Wong, E. García-Junada, L. Chen, O. Blanco, H. J. M. Gijsen, D. H. Steensma, J. Am. Chem. Soc. 1995, 117, 3333.

[9] a) B. List, R. A. Lerner, C. F. Barbas III, J. Am. Chem. Soc. 2000, 122, 2395; b) B. List, Synlett 2001, 1675; c) B. List, P. Pojarliev, C. Castello, Org. Lett. 2001, 3, 573 .

[10] a) U. Eder, G. Sauer, R. Wiechert, Angew. Chem. Int. Ed. Engl. 1971, 10, 496; b) Z. H. Hajos, D. R. Parrish, J. Org. Chem. 1974, 39, 1612 J. Am. Chem. Soc. 2003, 153, 16; b) C. Allemann, R. Gordillo, F. R. Clemente, P. H-Y. Cheong, K. N. Houk, Acc. Chem. Res. 2004, 37, 558. from proline, A. J. A. Cobb, D. M. Shaw, D. A. Longbottom, J. B. Gold, S. V. Ley, Org. Biomol. Chem. 2005, 3, 84; b) For tetrazole derived from proline, A. Hartikka, P. I. Arvidsson, Tetrahedron Asymmetry 2004, 15, 1831; c) For 4-substituted prolines, E. Bellis, G. Kokotos, Tetrahedron 2005, 61, 8669; d) For protonic acid, cyclic and acyclic 2-aminomethyl pyrrolidines, M. Nakadi, S. Saito, H. Yamamoto, Tetrahedron 2002, 58 , 8167; e) For benzoimidazole pyrrolidine, E. Lacoste, Y. Landais, K. Schenk, J.-B. Verlhac, J. M. Vincent, Tetrahedron Lett. 2004, 45, 8035 .

[13] a) A. Córdova, W. Zou, I. Ibrahen, E. Reyes, M. Engqvist, W. Liao, Chem. Commun. 2005, 3586; b) T. Kano, J. Takai, O. Tokuda, K. Maruoka, Angew. Chem. Int. Ed. 2005, 44, 3055; c) E. R. Jarvo, S. J. Miller, Tetrahedron 2002, 58, 2481; d) P. Dziedzic, W. Zou, J. Hafren, A. Córdova, Org. Biomol. Chem. 2006, 4, 38; e) J. Kofoed, J. Nielsen, J.-L. Reymond, Bioorg Med. Chem. Lett. 2003, 13, 2445.

[14] a) For 5,5-dimethyl thiazolidinium-4-carboxylate (DMTC), see: K. Sakthivel, W. Notz, T. Bui, C. F. Barbas III, J. Am. Chem. Soc. 2001, 123, 5260; b) For 2-tert-butyl-4-benzyl imidazolidinones, see: I. K. Mangion, A. B. Northrup, D. W. C. MacMillan, Angew. Chem. Int. Ed. 2004, 43, 6722; c) For $(1 R, 2 S)-2$ aminocyclopentanecarboxylic acid, see: S. G. Davies, R. L. Sheppard, A. D. Smith, J. E. Thomson, Chem. Commun. 2005, 3802.

[15] M. R. M. Andrae, A. P. Davis, Tetrahedron Asymmetry 2005, 16, 2487.

[16] J. T. Suri, B. R. Dhevalapally, C. F. Barbas III, Org. Lett. 2005, 7, 1383.

[17] a) E. Enders, C. Grondal, Angew. Chem. Int. Ed. 2005, 44, 1210; b) C. Grondal, E. Enders, Tetrahedron 2005, 62, 329; c) E. Enders, C. Grondal, Lett. Org. Chem. 2005, 2, 577.

[18] I. Ibrahen, A. Córdova, Tetrahedron Lett. 2005 , 46, 3363.
[11] a) L. Hoang, S. Bahmanyar, K. N. Houk, B. List,

[12] a) For tetrazole and acylsulfonamide derived
[19] A. B. Northrup, D. W. C. MacMillan, J. Am. Chem. Soc. 2002, 124, 6798

[20] A. B. Northrup, I. K. Mangion, F. Hettche, D W. C. MacMillan, Angew. Chem. Int. Ed. 2004 43, 2152.

[21] a) A. B. Northrup, D. W. C. MacMillan, Science 2004, 305, 1752; b) R. I. Storer, D. W. C. MacMillan, Tetrahedron 2004, 60, 7705.

[22] A. Córdova, I. Ibrahem, J. Casas, H. Sunden, M. Engqvist, E. Reyes, Chem. Eur. J. 2005, 11, 4772.

[23] J. Casas, M. Engqvist, I. Ibrahem, B. Kaynak, A. Córdova, Angew. Chem. Int. Ed. 2005, 44, 1343.

[24] a) A. Córdova, W. Notz, G. Zhong, J. M. Betancort, C. F. Barbas III, J. Am. Chem. Soc. 2002, 124, 1842; b) A. Córdova, S. Watanabe, F. Tanaka, W. Notz, C. F. Barbas III, J. Am. Chem. Soc. 2002, 124, 1866; c) W. Notz, K. Sakthivel, T. Bui, G. Zhong, C. F. Barbas III, Tetrahedron Lett. 2001, 42, 199.

[25] a) B. List, J. Am. Chem. Soc. 2000, 122, 9336 b) B. List, P. Pojarliev, W. T. Biller, H. J. Martin, J. Am. Chem. Soc. 2002, 124, 827.

[26] D. Enders, C. Grondal, M. Vrettou, G. Raabe, Angew. Chem. Int. Ed. 2005, 44, 4079.

[27] a) Y. Hayasi, W. Tsuboi, I. Ashimine, T. Urushima, M. Shoji, K. Sakai, Angew. Chem. Int. Ed. 2003, 42, 3677; b) For a review, see: M. M. B. Marques, Angew. Chem. Int. Ed. 2000, 45,348 .

[28] a) T. Mukaiyama, I. Shiina, S. Kobayashi, Chem. Lett. 1990, 2201; b) S. Kobayashi, T. Kawasuji, Synlett. 1993, 911.

[29] a) H. Kiliani, Ber. Deutsch. Chem. 1885, 18 , 3066; b) E. Fischer, Ber. Deutsch. Chem. 1889, 11, 2204; c) F. W. Lichtenthaler, Angew. Chem. Int. Engl. 1992, 31, 1541; d) J. Stanek, M. Cerny, J. Kocourek, J. Pacák, 'The Monosaccharides', Academic Press, New York, 1965; p. 144; e) R. Soengas, K. Izumori, M. I. Simone, D. J. Watkin, U. P. Skylte, W. Stoltaert, G. W. J. Fleet, Tetrahedron Lett. 2005, 46, 5755 and references cited therein; f) D. Hotschkiss, R. Soengas, M. I. Simone, J. van Amekjde, S. Hunter, A. R. G. W. J. Cowley, Fleet, Tetrahedron Lett. 2004, 45, 9461.

[30] a) W. R. Roush, L. K. Hoong, M. A. J. Palmer, J. A. Straub, A. D. Palkowitz, J. Org. Chem. 1990, 55, 4117; b) W. R. Roush, K. Ando, D. B. Powers, A. D. Palkowitz, R. L. Halterman, J. Am. Chem. Soc. 1990, 112, 6339; c) W. R. Roush, J. A. Straub, M. S. VanNieuwenhze, $J$. Org. Chem. 1991, 56, 1636; d) W. R. Roush, X Lin, J. A. Straub, J. Org. Chem. 1991, 56, 1649.

[31] a) K. Maruyama, Y. Ishihara, Y. Yamamoto, Tetrahedron Lett. 1981, 22, 4235; b) J. A. Marshall, G. P. Luke, J. Org. Chem. 1991, 56, 483; c) J. A. Marshall, Chem. Rev. 1996, 96, 31; d) J. Jurczak, S. Pikul, T. Bauer, Tetrahedron 1986, 42,447

[32] D. S. Matteson, M. L. Peterson, J. Org. Chem 1987, 52, 5116 .

[33] a) R. Oi, K. B. Sharpless, Tetrahedron Lett. 1992, 33, 2095; b) H. C. Kolb, M. S. VanNieuwenhze, K. B. Sharpless, Chem. Rev 1994, 94, 2483.

[34] a) A. Dondoni, A. Marra, in 'Preparative Carbohydrate Chemistry', Ed. S. Hanessian, Marcel Dekker, New York, 1997, pp 173; b) A Dondoni, Synthesis 1998, 1681; c) A. Dondoni, A. Marra, Chem. Commun. 1999, 2133; d) A. Dondoni, D. Perrone, Tetrahedron Lett. 1999, 40, 9375; e) A. Dondoni, A. Marra, Chem. Rev. 2000, 100, 4394; f) A. Dondoni, Pure Appl. Chem. 2000, 72, 1577; g) A. Dondoni, P. Formaglio, A. Marra, A. Massi, Tetrahedron 2001, 57, 7719; h) A. Dondoni, P. P. Giovannini, D. Perrone, J. Org. Chem. 2002, 67, 7203; i) A. Dondoni, P. P. Giovannini, Synthesis 2002 , 1701; j) A. Dondoni, A. Marra, Chem. Rev. 2004, 104, 2557. 
[35] a) A. Dondoni, G. Fantin, M. Fogagnolo, P. Pedrini, J. Org. Chem. 1990, 55, 1439; b) A Dondoni, D. Perrone, P. Merino, J. Org. Chem. 1995, 60, 8074

[36] a) A. Dondoni, S. Franco, F. Junquera, F. L. Merchán, P. Merino, T. Tejero, V. Bertolasi, Chem. Eur. J. 1995, 1, 505; b) A. Dondoni, S Franco, F. L. Merchán, P. Merino, T. Tejero, Tetrahedron Lett. 1993, 34, 5479; c) P. Merino, S. Franco, P. Merchán, T. Tejero, Tetrahedron Lett. 2002, 43, 459; d) A. Dondoni, P. P. Giovannini, D. Perrone, Org. Chem. 2002, 67, 7203.

[37] L. Benzing-Nguyen, M. B. Perry, J. Org. Chem. 1978, 43, 551 .

[38] M. Kusakabe, F. Sato, Chem. Lett. 1986, 1473.

[39] H. Chikashita, T. Nikaya, K. Itoh, Nat. Prod. Lett. 1993, 2, 183.

[40] a) G. Solladié, C. Frechou, J. Hutt, G. Demailly, Bull. Soc. Chim. Fr. 1987, 827. b) G. Solladié, G. Demailly, C. Greck, J. Org. Chem. 1985, 50, 1552.

[41] T. Mukaiyama, in 'Trends in Synthetic Carbohydrate Chemistry, ACS Symposium Series 386', Eds. D. Horton, L. D. Hawkins, G. D. McGarvey, American Chemical Society, Washington, 1989, Chapter 15, pp 278.

[42] R. Devant, U. Mahler, H. Braun, Chem. Ber. 1988, 121, 397.

[43] S. Gräf, M. Braun, Liebigs Ann. Chem. 1993, 1091.

[44] A. J. Rudge, I. Collina, A. B. Holmes, R. Baker, Angew. Chem. Int. Ed. Engl. 1994, 33, 2320.

[45] a) D. Enders, U. Jegelka, Tetrahedron Lett. 1993, 34, 2453; b) A. Job, C. F. Janeck, W Beltray, R. Peters, D. Enders, Tetrahedron 2002, 58, 2253.

[46] a) T. Katsuki, K. B. Sharpless, J. Am. Chem. Soc. 1980, 102, 5974; b) A. Pfenninger,
Synthesis 1986, 89; c) K. A. Jørgensen, Chem. Rev. 1989, 89, 431.

[47] a) T. Katsuki, A. W. M. Lee, P. Ma, V. S. Martin, S. Masamune, K. B. Sharpless, D. Tuddenham, F. J. Walker, J. Org. Chem. 1982, 47, 1373; b) P. Ma, V. S. Martin, S. Masamune, K. B. Sharpless, S. M. Viti, J. Org. Chem. 1982, 47, 1378.

[48] S. Y. Ko, A. W. M. Lee, S. Masamune, L. A. Reed III; K. B. Sharpless, F. J. Walker, Tetrahedron 1990, 46, 245.

[49] a) K. B. Sharpless, W. Amberg, Y. L. Bennani, G. A. Crispino, J. Hartiung, K.-S. Jung, H.-L. Kwong, K. Morikawa, Z.-M. Wang, D. Xu, X.L. Zhang, J. Org. Chem. 1992, 57, 2768; b) H. Becker, K. B. Sharpless, Angew. Chem. Int. Ed. Engl. 1996, 35, 448; c) G. Li, H.-T. Chang, K. B. Sharpless, Angew. Chem. Int. Ed. Engl. 1996, 451; d) M. Jørgensen, E. H. Iversen, R. Madsen, J. Org. Chem. 2001, 66, 4625.

[50] a) W. R. Roush, A. E. Walts, L. K. Hoong, J. Am. Chem. Soc. 1985, 107, 8186; b) W. R. Roush, R. L. Halterman, J. Am. Chem. Soc. 1986, 108, 294.

[51] a) W. R. Roush, J. A. Straub, Tetrahedron Lett. 1986, 27, 3349; b) W. R. Roush, J. A. Hunt, $J$. Org. Chem. 1995, 60, 798.

[52] S. J. Danishefsky, M. P. DeNinno, S.-H. Chen, J. Am. Chem. Soc. 1988, 110, 3929.

[53] a) D. A. Evans, J. S. Johnson, J. Am. Chem. Soc. 1998, 120, 4895; b) D. A. Evans, E. J. Olhava, J. S. Johnson, J. M. Janey, Angew. Chem. Int. Ed. 1998, 37, 3372; c) D. A. Evans, J. S. Johnson, E J. Olhava, J. Am. Chem Soc 2000, 122, 1635.

[54] J. Thorhauge, M. Johannsen, K. A. Jørgensen, Angew. Chem. Int. Ed. 1998, 37, 2404.

[55] H. Audrain, J. Thorhauge, R. G. Hazell, K. A. Jørgensen, J. Org. Chem. 2000, 65, 4487. 